\title{
Examining the relationship between vegetable intake of mothers and that of their children: a cross-sectional study of 10- to 12-year-old schoolchildren in Japan
}

\author{
Yuki Tada ${ }^{1, *}$, Yasutake Tomata ${ }^{2}$, Ayaka Sunami $^{3}$, Yuri Yokoyama $^{3}$, Azumi Hida ${ }^{1}$, \\ Tadasu Furusho ${ }^{4}$ and Yukari Kawano ${ }^{1}$ \\ 'Department of Nutritional Science, Faculty of Applied Bioscience, Tokyo University of Agriculture, Sakuragaoka 1-1-1, \\ Setagaya, Tokyo 156-8502, Japan: ${ }^{2}$ Tohoku University School of Public Health, Graduate School of Medicine, Sendai, \\ Japan: ${ }^{3}$ Graduate School of Agriculture, Tokyo University of Agriculture, Tokyo, Japan: ${ }^{4}$ Department of Nutrition, Junior \\ College of Tokyo University of Agriculture, Tokyo, Japan
}

Submitted 9 March 2015: Final revision received 27 July 2015: Accepted 6 August 2015: First published online 21 September 2015

\begin{abstract}
Objective: The present study aimed to investigate the correlation between mothers' and children's vegetable intake and whether children are conscious about their vegetable intake.

Design: Cross-sectional study. Self-administered questionnaires for mothers and children, consisting of items regarding diet history, were distributed to children via homeroom teachers. We created dummy exposure variables for each quartile of mothers' vegetable intake. Multiple regression analysis was performed with children's vegetable intake as the outcome variable.

Setting: Two public elementary schools in a residential district of Tokyo, Japan. Subjects: Study participants were upper-grade children (aged 10-12 years) and their mothers (332 pairs of mothers and children).

Results: The mean vegetable intake in mothers and children was 310 (SD 145) g/d and 276 (SD 105) g/d, respectively. A positive linear relationship was found between mothers' and children's vegetable intake even after adjustment for considerable covariates $(P<0 \cdot 001)$. When stratified by children's consciousness, the positive linear relationship was more pronounced in children who were conscious of eating all their vegetables $(P<0.001$ for interaction with children's consciousness).

Conclusions: Mothers' vegetable intake was significantly correlated with children's vegetable intake. However, this correlation was stronger in children who were conscious of eating all their vegetables. Our findings suggest that enhancing mother's vegetable intake and health consciousness of children are indispensable prerequisites for increasing vegetable intake among children.
\end{abstract}

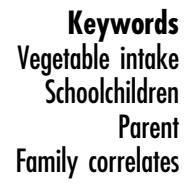

Childhood dietary habits are the determinants of diet in adulthood $^{(1)}$. As higher vegetable intake during childhood is associated with a lower risk of adult chronic disease ${ }^{(2)}$, it is important to develop consciously the habit of eating vegetables from childhood. However, data from the WHO Health Behaviour in School-aged Children Survey show that the average proportions of 11-year-olds who eat vegetables every day in each country and region are $36 \cdot 1 \%$ for girls and $30.5 \%$ for boys ${ }^{(3)}$. Similarly, in Japan, school lunch plate waste has a high ratio of vegetable dishes to grains or desserts ${ }^{(4)}$, and the vegetable intake of each age group does not reach the recommended quantity ${ }^{(5)}$. Therefore, while nutrition education is important for all generations, childhood nutrition education is of particular importance as it may exert great influence on the growth of children as well as prevention of future chronic diseases. Unfortunately, recent systematic reviews of interventions to increase vegetable intake among children have found that the optimal design components remain unclear ${ }^{(6)}$.

To increase vegetable intake among children, consideration should be given to the home food environment, as the majority of school-aged children eat at home except for school lunch. In a previous study, eating a balanced school lunch was associated with the availability of healthier foods at home and an overall healthier $\operatorname{diet}^{(7)}$, suggesting that healthy eating patterns are acquired at home. Thus, nutritional education conducted only at 
school might not increase vegetable intake among children. Exposing children to a variety of foods is the key to develop their dietary preference, and food availability, which usually depends on the parents, affects vegetable intake during childhood ${ }^{(7,8)}$, as most children would eat vegetables if parents prepare them. In this context, parents represent an environmental factor that determines children's vegetable intake. A recent review suggested that parental encouragement, family rules (demand/allow) and parental occupational status were positively associated with children's vegetable intake ${ }^{(9)}$. However, because variables that significantly correlate with children's vegetable intake differ between studies, it was inconclusive with regard to which factors were significantly associated. Certainly, mothers' vegetable intake may be affected by these factors and may serve as an important determinant of the home food environment, which may in turn influence children's diets. Therefore, the present study focuses on how mothers' vegetable intake may serve as a potential predictor of children's vegetable intake.

On the other hand, health behaviours are influenced by both personal factors (e.g. health consciousness) and the social environment (i.e. parental factors), as the model of triadic reciprocal causation suggests ${ }^{(10)}$. In this model, the environment, the individual and behavioural factors all operate as interacting determinants. Accordingly, not only parental factors but also children's health consciousness may play an important role in increasing vegetable intake among children. Consistent with this hypothesis, we speculate that children's consciousness of eating all their vegetables would modify the association between parental vegetable intake and children's vegetable intake. In other words, vegetable intake in children would not increase even if their parents were to eat a lot of vegetables, if children themselves are not conscious of the need to do so. Yet, few studies have simultaneously considered both parental and personal (children) factors.

The present study aimed to investigate the correlation between mothers' and children's vegetable intake and whether children are conscious of the need to eat vegetables.

\section{Methods}

A cross-sectional study of elementary-school children and their mothers was conducted.

\section{Participants}

Study participants were upper-grade children (aged 10-12 years) in two public elementary schools and their mothers in Setagaya ward, a residential area in Tokyo, Japan. Consistent with the Japanese school lunch programme offerings, both schools provided school lunch every weekday.

Responses were obtained from 362 of 463 pairs of children and their mothers who were asked to participate in the study (response rate: $78.2 \%$ ). Overall, the numbers of missing data or criteria violations in various categories were as follows: responses from grandmothers ( $n$ 2), non-entries in the dietary questionnaire $(n 4)$, different respondents for the dietary questionnaire and the general health questionnaire ( $n$ 20), and missing data regarding mothers' employment status ( $n$ ) or children's weight and height ( $n$ 3). A total of 332 respondent questionnaires were analysed.

\section{Data collection}

Self-administered questionnaires for mothers and children consisting of items regarding background characteristics, factors that may influence children's vegetable intake and diet history were put into an envelope, together with explanations of the study purpose and methodology and a consent form. These envelopes were distributed to children via homeroom teachers in July 2012. Children handed the questionnaire to their mothers at home.

\section{Measures}

\section{Vegetable intake}

In mothers, vegetable intake and total energy intake were assessed with a validated self-administered brief diet history questionnaire (BDHQ) ${ }^{(11,12)}$. The BDHQ surveys the consumption frequency of a total of fifty-eight food and beverage items, with specified serving sizes described in terms of the natural portion or standard weight and volume measurement of servings commonly consumed in the general Japanese populations. In the BDHQ, vegetable intake is estimated by the sum of green and yellow vegetables (three types), other vegetables (four types) and pickled vegetables (two types). Regarding validity of the BDHQ for adult women, Spearman's correlation coefficients for the amount of vegetable intake by the dietary record method were 0.57 for green and yellow vegetables, 0.39 for other vegetables and 0.78 for pickled vegetables ${ }^{(12)}$.

In children, vegetable intake and total energy intake were assessed with a modified version of the BDHQ (BDHQ-10y), which takes into account the readability of the questionnaire and knowledge of foods among older children and adolescents ${ }^{(13)}$. The cover sheet of the BDHQ-10y instructs children to answer each question based on their past month's activity, without over-thinking, and when the question is too difficult, children are instructed to work together with their guardians. Vegetable intake adjusted for total energy intake was calculated by the residual method ${ }^{(14)}$.

\section{Participant characteristics and lifestyle habits}

A written questionnaire was developed based on background characteristics and lifestyle habits that may influence children's vegetable intake. Information regarding mother's age, employment, height, weight, preventive behaviours for lifestyle-related diseases (yes/no) and frequency of eating breakfast was obtained from the self-administered 
questionnaire for mothers. Information regarding children's height, weight, frequency of eating breakfast, start and end time for breakfast and dinner, and frequency and contents of outdoor play time was obtained using the self-administered questionnaire for children. In this questionnaire, children were also asked 'Are you conscious of eating all vegetables?', and given the options of 'Yes' or 'No'. The exercise intensity of outdoor play activity was classified as $<3$ MET or $\geq 3 \mathrm{MET}^{(15)}$ (where MET = metabolic equivalent of task). The questionnaire items were based on the survey for school-aged children conducted by a government-affiliated organization ${ }^{(16)}$ and the National Health and Nutrition Survey ${ }^{(17)}$.

Mothers' degree of obesity was assessed by BMI calculated by dividing self-reported weight (in kilograms) by self-reported height (in metres) squared, and categorized as underweight $\left(<18.5 \mathrm{~kg} / \mathrm{m}^{2}\right)$, normal $\left(18.5-24.9 \mathrm{~kg} / \mathrm{m}^{2}\right)$ and obese $\left(\geq 25 \mathrm{~kg} / \mathrm{m}^{2}\right)^{(18)}$. Children's degree of obesity was calculated as [weight $(\mathrm{kg})$ - reference weight for height $(\mathrm{kg})] /[$ reference weight for height $(\mathrm{kg})] \times 100(\%)$ according to the methods of School Health Statistics Research, and classified into underweight trend $(<-20 \%)$, normal $(-19$ to $19 \%)$ and obesity trend $(\geq 20 \%)^{(19)}$.

\section{Statistical analysis}

Participant characteristics were compared between quartile groups of mother's vegetable intake using the $\chi^{2}$ test for categorical variables and one-factor ANOVA for continuous variables. Multiple regression analysis was performed with children's vegetable intake as the outcome variable and mothers' vegetable intake as the exposure variable. We examined the relationship between mothers' and children's vegetable intake by using the following models: Model 1, which adjusted for mothers' age and children's age and sex; and Model 2, in which each variable was adjusted for mothers' age, employment and BMI, and children's age, sex, degree of obesity and school. Because variables that correlate significantly with children's vegetable intake differ between studies ${ }^{(9)}$, we chose the minimum number of confounding factors from the basic characteristics of participants.

To assess the interaction effect of children's consciousness to eat all their vegetables, we tested for interactions and then stratified participants by children's consciousness according to Model 2, excluding nine participants with missing data ( $n$ 323).

All statistical analyses were performed with the statistical software package IBM SPSS $20 \cdot 0$ for Windows. $P<0.05$ was considered statistically significant using two-tailed tests.

\section{Results}

Mean age for mothers and children was 42.9 (SD 3.9) years and 10.9 (SD 0.7) years, respectively. Among the mothers, $41.6 \%$ were not working. Among the children, 54.8\% were boys and $92.2 \%$ had normal weight. Mean vegetable intake for all participants, mothers and children was 293 (SD 128) g/d, 310 (sD 145) g/d and 276 (sD 105) g/d, respectively. Characteristics of mothers and their children are shown in Table 1. Mothers who consumed larger amounts of vegetables were more likely to behave in ways that help to prevent lifestyle-related diseases. These behaviours help prevent lifestyle-related diseases through restriction of energy intake, consumption of large amounts of vegetables and reduction in salt intake.

The coefficients of vegetable intake for mothers and children used in multiple linear regression models are shown in Table 2. A positive linear relationship was observed between mothers' and children's vegetable intake, even after adjustment for covariates $(P<0.001$ in Model 2). $R^{2}$ values for the crude model, Model 1 and Model 2 were $0 \cdot 165,0 \cdot 172$ and $0 \cdot 184$, respectively.

The coefficients of mothers' vegetable intake stratified by children's consciousness are shown in Table 3. We observed the quantitative interaction that the positive linear relationship was more pronounced in children who were conscious of eating all their vegetables $(P<0.001$ for interaction with children's consciousness).

\section{Discussion}

The present study aimed to investigate the correlation between mothers' and children's vegetable intake and whether children are conscious of the need for vegetable intake. The results showed that increased vegetable intake in children was positively associated with mothers' vegetable intake, especially among children who were conscious of eating all their vegetables. The present study is one of few studies conducted in Japan that explored the correlates of vegetable consumption among elementaryschool children.

Vegetable intake levels among the mothers and children in the present study were consistent with findings of most other studies reported to date ${ }^{(20-23)}$. Although some studies have shown no relationship between mothers' and children's vegetable consumption ${ }^{(24-26)}$, those studies used different methods to assess vegetable intake in parents and children, and thus did not yield comparable results. We assessed the vegetable intake in mothers with the previously validated BDHQ, and that in children using the BDHQ-10y, a modified version of the BDHQ for older children and adolescents. We thereby addressed the issue of inconsistency in assessment method such that our findings could contribute to the data in this field.

The relationship between parental and childhood vegetable intake can be explained by parental modelling, as well as children's tendency to imitate their parents, consciously or unconsciously. According to the PRECEDE-PROCEDE model, predisposing factors that facilitate or hinder motivation for health behaviour include early childhood experiences 
Table 1 Participant characteristics according to quartile groups of mothers' vegetable intake; upper-grade children (aged 10-12 years) in two public elementary schools and their mothers (332 pairs of mothers and children), Tokyo, Japan, July 2012

\begin{tabular}{|c|c|c|c|c|c|c|c|c|c|}
\hline & \multicolumn{8}{|c|}{ Mothers' vegetable intake $(\mathrm{g} / \mathrm{d})^{\star}$} & \multirow[b]{3}{*}{$P+$} \\
\hline & \multicolumn{2}{|c|}{ Q1 } & \multicolumn{2}{|c|}{ Q2 } & \multicolumn{2}{|c|}{ Q3 } & \multicolumn{2}{|c|}{ Q4 } & \\
\hline & $n$ or Mean & $\%$ or SD & $n$ or Mean & $\%$ or SD & $n$ or Mean & $\%$ or SD & $n$ or Mean & $\%$ or SD & \\
\hline \multicolumn{10}{|l|}{ Children's characteristics } \\
\hline \multicolumn{10}{|l|}{ Degree of obesity } \\
\hline Underweight trend & 2 & 2.4 & 3 & 3.6 & 5 & $6 \cdot 0$ & 2 & $2 \cdot 4$ & \multirow[t]{3}{*}{0.607} \\
\hline Normal & 75 & 90.4 & 78 & 94.0 & 75 & 90.4 & 78 & 94.0 & \\
\hline Obese trend & 6 & $7 \cdot 2$ & 2 & 2.4 & 3 & 3.6 & 3 & 3.6 & \\
\hline \multicolumn{10}{|c|}{ Frequency of eating breakfast } \\
\hline 0-6 times/week & 6 & $7 \cdot 2$ & 3 & 3.6 & 5 & $6 \cdot 0$ & 0 & 0.0 & \multirow[t]{2}{*}{0.062} \\
\hline Every day & 77 & 92.8 & 80 & 96.4 & 78 & $94 \cdot 0$ & 83 & $100 \cdot 0$ & \\
\hline \multicolumn{10}{|l|}{ Minutes spent for breakfast } \\
\hline$<15$ & 56 & 67.5 & 38 & 46.9 & 46 & $56 \cdot 1$ & 41 & $50 \cdot 6$ & \multirow[t]{3}{*}{0.170} \\
\hline $15-20$ & 18 & $21 \cdot 7$ & 26 & $32 \cdot 1$ & 23 & 28.0 & 22 & $27 \cdot 2$ & \\
\hline$\geq 21$ & 9 & $10 \cdot 8$ & 17 & $21 \cdot 0$ & 13 & $15 \cdot 9$ & 18 & $22 \cdot 2$ & \\
\hline \multicolumn{10}{|l|}{ Minutes spent for dinner } \\
\hline$<29$ & 17 & 20.5 & 17 & $21 \cdot 0$ & 17 & $20 \cdot 7$ & 14 & $17 \cdot 3$ & \multirow[t]{3}{*}{0.738} \\
\hline 30 & 43 & 51.8 & 36 & 44.4 & 33 & $40 \cdot 2$ & 41 & $50 \cdot 6$ & \\
\hline$\geq 31$ & 23 & $27 \cdot 7$ & 28 & 34.6 & 32 & $39 \cdot 0$ & 26 & $32 \cdot 1$ & \\
\hline \multicolumn{10}{|c|}{ Frequency of outdoor play-time activity (activity $\geq 3 \mathrm{MET}$ ) } \\
\hline Not every day & 59 & $71 \cdot \overline{1}$ & 61 & 73.5 & 59 & $71 \cdot 1$ & 49 & $59 \cdot 0$ & \multirow[t]{2}{*}{$0 \cdot 180$} \\
\hline Every day & 24 & 28.9 & 22 & 26.5 & 24 & 28.9 & 34 & 41.0 & \\
\hline \multicolumn{10}{|c|}{ Conscious of eating all vegetables } \\
\hline Yes & 60 & $76 \cdot 9$ & 65 & $78 \cdot 3$ & 68 & $84 \cdot 0$ & 74 & 91.4 & \multirow[t]{2}{*}{0.064} \\
\hline No & 18 & 23.1 & 18 & 21.7 & 13 & $16 \cdot 0$ & 7 & 8.6 & \\
\hline \multicolumn{10}{|l|}{ Mothers' characteristics } \\
\hline $\begin{array}{l}\text { Age (years), mean and SD } \\
\text { Employment }\end{array}$ & & 0.082 \\
\hline Not working & 33 & $39 \cdot 8$ & 32 & 38.6 & 33 & $39 \cdot 8$ & 40 & $48 \cdot 2$ & \multirow[t]{3}{*}{0.608} \\
\hline Part-time work & 29 & 34.9 & 31 & $37 \cdot 3$ & 34 & 41.0 & 31 & 37.3 & \\
\hline Full-time work & 21 & $25 \cdot 3$ & 20 & $24 \cdot 1$ & 16 & $19 \cdot 3$ & 12 & 14.5 & \\
\hline \multicolumn{10}{|l|}{ BMI } \\
\hline$<18.5 \mathrm{~kg} / \mathrm{m}^{2}$ & 12 & 14.5 & 15 & $18 \cdot 1$ & 11 & 13.3 & 17 & 20.5 & \multirow[t]{3}{*}{0.650} \\
\hline $18.5-25.0 \mathrm{~kg} / \mathrm{m}^{2}$ & 61 & 73.5 & 60 & $72 \cdot 3$ & 67 & $80 \cdot 7$ & 60 & $72 \cdot 3$ & \\
\hline$\geq 25.0 \mathrm{~kg} / \mathrm{m}^{2}$ & 10 & $12 \cdot 0$ & 8 & 9.6 & 5 & $6 \cdot 0$ & 6 & $7 \cdot 2$ & \\
\hline Behaviours preventive of li & style-related & diseasesł & & & & & & & \\
\hline Yes & 32 & 39.5 & 32 & 41.6 & 45 & $60 \cdot 8$ & 53 & $66 \cdot 3$ & $<0.001$ \\
\hline No & 49 & 60.5 & 45 & 58.4 & 29 & 39.2 & 27 & 33.8 & \\
\hline Frequency of eating break & & & & & & & & & \\
\hline 0-6 times/week & 19 & $22 \cdot 9$ & 17 & 20.5 & 14 & $16 \cdot 9$ & 11 & $13 \cdot 3$ & 0.408 \\
\hline Every day & 64 & $77 \cdot 1$ & 66 & 79.5 & 69 & 83.1 & 72 & $86 \cdot 7$ & \\
\hline
\end{tabular}

MET, metabolic equivalent of task.

Data presented are numbers and percentages, unless indicated otherwise.

*Adjusted for energy intake using the residual method. $n 83$ each for Q1-Q4, with the exception of missing values. Mean intake (g/d): 158 (sD 48 ) in Q1, 256 (SD 20) in Q2, 332 (SD 27) in Q3, 497 (sD 138) in Q4 $(P<0.001)$.

†Obtained by using the $x^{2}$ test for categorical variables and one-factor ANOVA for continuous variables.

łBehaviours such as energy restriction, eating a large amount of vegetables and reduced salt intake.

Table 2 Coefficients of mothers' vegetable intake ${ }^{\star}, \dagger v$. children's vegetable intake ${ }^{*} \dagger$ in multiple linear regression models; upper-grade children (aged 10-12 years) in two public elementary schools and their mothers (332 pairs of mothers and children), Tokyo, Japan, July 2012

\begin{tabular}{lccc}
\hline & Linear regression coefficient & SE & $P$ \\
\hline Crude & 0.295 & 0.037 & $<0.001$ \\
Model 1 & 0.287 & 0.037 & $<0.001$ \\
Model 2§ & 0.285 & 0.037 & $<0.001$ \\
\hline
\end{tabular}

*Adjusted for energy intake using the residual method.

†Vegetable intake per day.

$\ddagger$ Adjusted for mothers' age (continuous) and children’s age (continuous) and sex (male, female).

$\S$ Adjusted for mothers' characteristics (age (continuous), employment (not working, part-time, full-time), BMl (continuous)) and children's characteristics (age (continuous), sex (male, female), degree of obesity (continuous) and school $(1,2)$ ). that create attitudes, values and perceptions ${ }^{(27)}$. Parental behaviours, attitudes and feeding styles contribute to their children's dietary environment ${ }^{(8)}$. A previous study regarding the parental effects on children showed that amounts of food served to children are related to amounts of food parents served to themselves ${ }^{(28)}$. Characteristics of the home food environment accounted for $48 \%$ of the variation in the child's fruit and vegetable score ${ }^{(29)}$. As such, the correlation between vegetable intake by mothers and children highlights the importance of education and support for mothers in increasing the children's vegetable intake. In an experimental study, a web-based mother-child dyad education programme for the prevention of childhood obesity induced changes in 


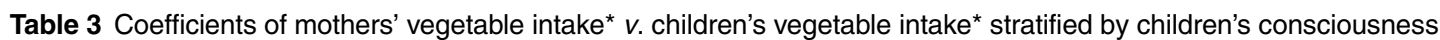
to eat all their vegetables; upper-grade children (aged 10-12 years) in two public elementary schools and their mothers (323 pairs of mothers and children), Tokyo, Japan, July 2012

\begin{tabular}{lccrc}
\hline & Linear regression coefficient† & SE & $P$ & $P$ for interaction \\
\hline Children's consciousness to eat all vegetables & 0.292 & & & $<0.001$ \\
Conscious $(n$ 267) & 0.251 & 0.042 & $<0.001$ & \\
Not conscious $(n$ 56) & 0.111 & 0.028 & \\
\hline
\end{tabular}

*Adjusted for energy intake using the residual method.

†Adjusted according to Model 2 in Table 2.

the home environment and facilitated an increase in fruit and vegetable intake among children of pre-school age ${ }^{(30)}$. Further investigation into educational programmes is needed to increase vegetable intake among both mothers and school-aged children.

Notably, correlations between vegetable intake by mothers and children were limited by the children's lack of consciousness to eat all of their vegetables. This finding was thought to suffice as support for the model of triadic reciprocal causation, which focuses on both social environment and personal factors to change health behaviours ${ }^{(10)}$. Thus, nutrition education to increase vegetable intake in children should focus both on environmental factors (e.g. increasing vegetable intake among mothers) and personal factors (e.g. a child's consciousness about needing to eat vegetables).

Our findings have practical implications for increasing vegetable intake among children. Interventions to motivate children to increase vegetable intake could be more effective if combined with strategies to increase vegetable intake in their mothers.

There were some limitations to the present study. First, dietary intake was estimated using self-administered diet history questionnaires, which were distributed at school. This might have affected the respondents in such a way that they felt inclined to give socially desirable responses. In addition, the validity of estimating energy intake by BDHQ-10y is still unclear. Thus, the results should be interpreted with caution. Second, mothers might have helped their children fill out the questionnaires, especially the diet history questionnaire, leading to an overestimation of the association between mothers' and children's vegetable intake. However, it is unlikely that this situation occurred frequently, given that the children were aged 10-12 years and thus should be considered reliable reporters of their own food intake ${ }^{(31)}$. In addition to this, children and mothers were provided with separate questionnaires. Third, participants lived in a residential district, with little farming grounds and limited access to fresh vegetables and agricultural experiences which can increase vegetable intake ${ }^{(32)}$. This environment might have also led to an overestimation of the association between the vegetable intake of mothers and their children. Fourth, the participants made up only about $0.014 \%$ of all students of the same age in Japan. As compared with large sample surveys in Japan ${ }^{(5,16)}$, participant characteristics revealed that the intake of vegetables for both mothers and children was higher, the ratio of mothers and children who ate breakfast every day was higher, mother's BMI was lower and children with obese trend were fewer. This may have limited the generalizability of our findings. Further, the statistical power also may be limited, particularly for children who were not conscious of eating all their vegetables. Future studies involving a greater sample size are warranted. Finally, because the $R^{2}$ of Model 2 was somewhat low, there is the possibility that all confounding factors were not accounted for. For example, although we could not obtain information regarding the economic status of participants, it has been indicated that economic situation is associated with vegetable intake in the National Health and Nutrition Survey in Japan.

\section{Conclusions}

The present study found that increased vegetable intake in children was positively associated with vegetable intake in mothers, especially among children who were conscious of eating all their vegetables. Our findings underscore the need to consider not only education for children at school, but also improvements in the home food environment to increase vegetable intake among children. In particular, mothers' vegetable intake should be increased concurrently to increase children's motivation to eat a lot of vegetables.

\section{Acknowledgements}

Acknowledgements: The authors would like to thank elementary-school principals and vice principals M. Miyamoto, T. Miyata, J. Usui and L. Shimazaki for their support in implementing the present study. Financial support: This research received no specific grant from any funding agency in the public, commercial or not-for-profit sectors. Conflict of interest: The authors declare no conflicts of interest. Authorship: Y. Tada, Y.K. and T.F. designed the research; Y. Tada, A.S., Y.Y., A.H. and T.F. conducted the research; Y. Tada and Y. Tomata analysed the data; Y. Tada and Y.K. wrote the manuscript; Y. Tada assumes primary responsibility for the final content. All authors have 
read and approve of the final manuscript. Ethics of buman subject participation: Ethical approval was obtained from the Research Ethics Committees of Tokyo University of Agriculture (reference number 1115). The purpose and methods of this study were explained to parents at a meeting in each class. All participants submitted their written informed consent along with their questionnaires.

\section{References}

1. Mikkila V, Rasanen L, Raitakari OT et al. (2004) Longitudinal changes in diet from childhood into adulthood with respect to risk of cardiovascular diseases: the Cardiovascular Risk in Young Finns Study. Eur J Clin Nutr 58, 1038-1045.

2. Ness AR, Maynard M, Frankel S et al. (2005) Diet in childhood and adult cardiovascular and all cause mortality: the Boyd Orr cohort. Heart 91, 894-898.

3. World Health Organization (2004) Young people's health in context. Health Behaviour in School-aged Children (HBSC) study: international report from the 2001/2002 survey. http://www.euro.who.int/_data/assets/pdf_file/0008/110231/ e82923.pdf (accessed January 2015).

4. Tada Y, Umemoto H, Ikeda M et al. (2012) Relationship between plate waste ratio and food category or serving amount in elementary school lunches. JJpn Soc Syokuiku 6, 365-374.

5. Ministry of Health, Labor and Welfare (2012) Results from 2011 National Health and Nutrition Survey. http://www.mhlw.go.jp/ bunya/kenkou/eiyou/h23-houkoku.html (accessed February 2013).

6. Diep CS, Chen TA, Davies VF et al. (2014) Influence of behavioral theory on fruit and vegetable intervention effectiveness among children: a meta-analysis. J Nutr Educ Behav 46, 506-546.

7. Tilles-Tirkkonen T, Pentikainen S, Lappi J et al. (2011) The quality of school lunch consumed reflects overall eating patterns in 11-16-year-old schoolchildren in Finland. Public Health Nutr 14, 2092-2098.

8. Patrick H \& Nicklas TA (2005) A review of family and social determinants of children's eating patterns and diet quality. $J$ Am Coll Nutr 24, 83-92.

9. Pearson N, Biddle SJ \& Gorely T (2009) Family correlates of fruit and vegetable consumption in children and adolescents: a systematic review. Public Health Nutr 12, 267-283.

10. Bandura A (2001) Social cognitive theory: an agentic perspective. Annu Rev Psychol 52, 1-26.

11. Kobayashi S, Murakami K, Sasaki S et al. (2011) Comparison of relative validity of food group intakes estimated by comprehensive and brief-type self-administered diet history questionnaires against $16 \mathrm{~d}$ dietary records in Japanese adults. Public Health Nutr 14, 1200-1211.

12. Kobayashi S, Honda S, Murakami K et al. (2012) Both comprehensive and brief self-administered diet history questionnaires satisfactorily rank nutrient intakes in Japanese adults. J Epidemiol 22, 151-159.

13. Okuda M, Sasaki S, Bando N et al. (2009) Carotenoid, tocopherol, and fatty acid biomarkers and dietary intake estimated by using a brief self-administered diet history questionnaire for older Japanese children and adolescents. J Nutr Sci Vitaminol 55, 231-241.

14. Willett W \& Stampfer MJ (1986) Total energy intake: implications for epidemiologic analyses. Am J Epidemiol 124, 17-27.
15. Ridley K, Ainsworth BE \& Olds TS (2008) Development of a compendium of energy expenditures for youth. Int J Behav Nutr Phys Act 5, 45.

16. National Agency for the Advancement of Sports and Health (2007) Report of Survey on Dietary Life Condition of School Aged Children. Tokyo: National Agency for the Advancement of Sports and Health (in Japanese).

17. Ministry of Health, Labor and Welfare (2011) Results from 2010 National Health and Nutrition Survey. http://www. mhlw.go.jp/stf/houdou/2r98520000020qbb.html (accessed June 2015).

18. Committee of Criteria for Obesity Disease, Japan Society for the Study of Obesity (2011) Criteria for obesity disease 2011. JJpn Soc Stud Obes 17, 1-78.

19. Japanese Society of School Health, National Agency for the Advancement of Sports and Health (2008) Manual of Health Checkup for School Aged Children. Tokyo: DAI-ICHI HOKI (in Japanese).

20. Bere E \& Klepp KI (2004) Correlates of fruit and vegetable intake among Norwegian schoolchildren: parental and selfreports. Public Health Nutr 7, 991-998.

21. Hannon PA, Bowen DJ, Moinpour CM et al. (2003) Correlations in perceived food use between the family food preparer and their spouses and children. Appetite $\mathbf{4 0}$, $77-83$.

22. Longbottom PJ, Wrieden WL \& Pine CM (2002) Is there a relationship between the food intakes of Scottish 5(1/2)-8 (1/2)-year-olds and those of their mothers? J Hum Nutr Diet 15, 271-279.

23. Reinaerts E, de Nooijer J, Candel M et al. (2007) Explaining school children's fruit and vegetable consumption: the contributions of availability, accessibility, exposure, parental consumption and habit in addition to psychosocial factors. Appetite 48, 248-258.

24. Djuric Z, Cadwell WF, Heilbrun LK et al. (2006) Relationships of psychosocial factors to dietary intakes of preadolescent girls from diverse backgrounds. Matern Child Nutr 2, 79-90.

25. Gibson EL, Wardle J \& Watts CJ (1998) Fruit and vegetable consumption, nutritional knowledge and beliefs in mothers and children. Appetite 31, 205-228.

26. Hanson NI, Neumark-Sztainer D, Eisenberg ME et al. (2005) Associations between parental report of the home food environment and adolescent intakes of fruits, vegetables and dairy foods. Public Health Nutr 8, 77-85.

27. Green LW \& Kreuter MW (2004) Health Program Planning: An Educational and Ecological Approach. New York: McGraw-Hill Humanities.

28. Johnson SL, Hughes SO, Cui X et al. (2014) Portion sizes for children are predicted by parental characteristics and the amounts parents serve themselves. Am J Clin Nutr 99, 763-770.

29. Wyse R, Campbell E, Nathan N et al. (2011) Associations between characteristics of the home food environment and fruit and vegetable intake in preschool children: a crosssectional study. BMC Public Health 11, 938.

30. Knowlden AP, Sharma M, Cottrell RR et al. (2015) Impact evaluation of enabling mothers to prevent pediatric obesity through web-based education and reciprocal determinism (EMPOWER) randomized control trial. Health Educ Behav 42, 171-184.

31. Livingstone MB \& Robson PJ (2000) Measurement of dietary intake in children. Proc Nutr Soc 59, 279-293.

32. Lautenschlager L \& Smith C (2007) Understanding gardening and dietary habits among youth garden program participants using the Theory of Planned Behavior. Appetite 49, 122-130. 